\title{
Beyond the Is/Ought Divide: Studying the Nature of the Bioethical Enterprise
}

\author{
Sarah Chan · John Coggon
}

Published online: 6 January 2013

(C) Springer Science+Business Media New York 2013

\section{Introduction}

This journal special issue, with five papers from an impressively multi-disciplinary authorship, follows a conference hosted in Manchester by the Institute for Science, Ethics, and Innovation that examined methods in bioethics. The discussions at that meeting focused on questions of inter-, multi-, post-, pan-, and trans-disciplinarity, and necessarily led to deep reflection on the very nature and value of bioethics itself: reinvigorating questions about methods seemed impossible without also exploring questions of scholarly identity and self-reflection. As such, the short discussion in this editorial, and the much more engaged arguments in the papers that follow, are advanced as a contribution to the growing literature that examines what we, as bioethics scholars in the field, do, and how we go about doing it.

The publication comes at a time when questions of methodology and disciplinarity are achieving increasing prominence. Much of this attention has focused in particular on the role of empirical research in bioethics; the apparent emergence of the 'empirical turn'. This gives rise to questions about the is/ought divide, of whether there can be such a thing as 'empirical ethics', of what exactly such an endeavour might consist in, and what the proper place is of the social sciences, especially sociology, within bioethics. Yet the problems of definition, scope, aims and approach that scholars in bioethics are currently facing go beyond a simple disciplinary binary or rivalry, to more profound exploration of the very nature of the bioethical enterprise itself. Indeed, scholars are coming to question whether it is even coherent to talk of the bioethical enterprise.

\section{S. Chan}

Institute for Science, Ethics, and Innovation, University of Manchester, Manchester M13 9PL, UK e-mail: Sarah.Chan@manchester.ac.uk

\section{J. Coggon ( $(\bowtie)$}

Southampton Law School, University of Southampton, Highfield, Southampton SO17 1BJ, UK

e-mail: John.Coggon@soton.ac.uk 
In the following five papers, the authors provide some fascinating arguments and insights on these questions. In some places, we find levels of harmony and agreement, but as much can be learned from points of tension between the contributors. The articles begin with a paper by Nicky Priaulx, who challenges the very notion that we should seek to identify (or take it that there is any substantive, singular concept of) 'the bioethicist'. Such an idea would imply that bioethics works as a single discipline, yet that is clearly not the case. Rather, bioethics is a field, and those working in it have different disciplinary expertise. As a community this range is broad, but as individual scholars we each represent one, or a small number of disciplines. Priaulx argues that by taking bioethics to be an 'expert community', we both sharpen our understanding of why defining 'the bioethicist' is unhelpful, and we focus more keenly on the expertise and methods that any individual working in bioethics brings to the enterprise. As such, we should not be searching for 'the method' of bioethics, or worrying to define 'the bioethicist'.

In some contrast, Iain Brassington argues that whilst there may be a place for the various disciplines that are drawn into bioethics, there is a central and privileged role for philosophers. On this view, bioethics is a particular branch of ethics, and should be understood as being part of moral philosophy. Anticipating and responding to objections to his position, Brassington emphasises the purpose of bioethics as being to produce action-guiding advice given concerns for morality. To do this well requires analytical skills, he argues, that are found in philosophical training and the understanding that that gives of normative theory.

Martyn Pickersgill's paper places an alternative emphasis on where part of our concern should be focused. Recognising that there is already a considerable breadth to the disciplines engaged in bioethics, Pickersgill invites us to consider further methodological, and other, insights that could valuably be drawn by looking at Science and Technology Studies (STS). Furthermore, engagement with STS can help teach us about ethics as a real dimension of the work of scientists and clinicians. Given what we have said above about the plural accounts of bioethics, it may perhaps seem a field that would naturally benefit through the expansion that Pickersgill argues for. He notes various limitations to his proposal, not least that both bioethics and STS are big and diverse fields, each with only limited claims to coherence from a disciplinary perspective. This may limit the chance of sound mutual understanding between the two. Nevertheless, his proposal is an important call in the context of discussions of methods in bioethics, and in understanding the nature and value of bioethical inquiry.

Toby Seddon provides an argument that follows usefully from Pickersgill's. Seddon, a criminologist who works in regulatory theory, would almost certainly not be thought of as an archetypal bioethicist. By approaching and addressing the field from 'outside', he brings an extremely useful perspective, one that is underscored by his presentation of regulatory theory and its potential application in bioethical analyses. Seddon provides an account of the development of study in regulation, and is clear about who (in a disciplinary sense) and what contributes to it. In so doing, he exposes a whole tranche of methods and considerations whose importance have a clear practical bearing within bioethics. He tackles this head on. We have seen, and Seddon clearly outlines, that there are debates about the challenges of a 
multi-disciplinary field, including the (probable) lack of communication, clarity, and precision relative to what one finds within a single discipline. He notes too the epistemological challenges, both in the generation of knowledge and in the assessment of its validity. His discussion of regulation shows how these challenges can productively and pragmatically be met in a valuable research enterprise, which he describes as 'cross-cutting'.

In the final paper, Mark Sheehan and Michael Dunn explore the value and validity of the sociology of bioethics, which they take to denote the study of people working in bioethics, as opposed to sociological methods being incorporated in bioethics in a research agenda that would address bioethical problems. Sheehan and Dunn's paper provides an important characterisation of bioethics itself, which raises a crucial challenge to sociologists of bioethics (and others), who may too easily presume an account of what bioethics is. For Sheehan and Dunn, bioethics can not simply be about ethical questions, but must more specifically be about ethical questions within a specific, practical context. This means that you find 'ought questions', but also 'secondary questions' that give us a proper and necessary grip on the practical context; questions, for example, about the social and regulatory context within which a practical moral imperative would be argued to apply. As such, a great deal of discussion of methods can be side-stepped, because Sheehan and Dunn's characterisation makes clear that there is a role for an enormous range of methods and approaches. Emphatically, then, bioethics is a field of inquiry, not a discipline or sub-discipline. An upshot of their account is that whilst sociology in bioethics has a clear place, for sociologists of bioethics to be part of, and contributors to, the field, they must do more than simply observe the practice of (what we might loosely label) 'bioethicists', and connect with 'ought questions'.

\section{Agreements, Disagreements, and Further Questions}

Certainly, there is some common ground at the heart of the multiple ways in which the term 'bioethics' is used; some shared understanding that exists at the core, whilst problems may arise at the margins. In light of the analysis in this journal issue, and our wider discussions, we would like to make several observations. Perhaps foremost is that the debates on bioethics' identity and methods can themselves reinforce various myths that cloud our thinking. First amongst these is the characterisation (some might say caricature) of differing forms of research on bioethical issues as binary or polar opposites: 'is' versus 'ought'; 'why' versus 'whether'; explanatory or descriptive versus normative or prescriptive; valueneutral versus value-laden. In our view, engagement in normative analysis does not and should not rule out drawing on descriptive analysis; meanwhile, empirical does not imply value-free or even value-neutral. Social research is necessarily socially contingent and contextualised. By the same token, philosophy is not neutral in its influences or with respect to social context. This being the case, it is not obvious that we can privilege or prioritise any discipline within bioethics-most contentiously, perhaps, not even moral philosophy. 
One point on which there does seem to be consensus among the various authors relates to the aims of the 'bioethical enterprise'; that it should be in some way relevant to policy and practice. Whilst the authors do not all agree on whether this feature is necessarily definitive of bioethics in that something cannot properly be described as bioethics without it, or whether this is simply one of a group of loosely related things that bioethics 'does', it seems to be a common theme: bioethics can (if not must) have some potential for real-world application. Priaulx, for example, describes bioethics as "more than an academic enterprise"; Pickersgill refers to the perceived "status of the bioethicist as an expert who occupies a privileged role in the governance of biomedicine"; Seddon takes as his starting point the need for a functional approach to practical problems as paving the way for a confluence of disciplines (of which bioethics may represent a part). Sheehan and Dunn pose a more stringent requirement for applicability by way of a results-based criterion: that whatever we want to call bioethics must have normative policy implications. At perhaps the other end of the spectrum (on this issue at least), even Brassington, whilst defending the role for theoretical philosophising and consideration of seemingly abstract issues, concedes that part of the justification for "debates that might appear facile or peripheral" is that they may be "indirectly important to the consideration of more apparently pressing issues". This common ground on the aims of bioethics can perhaps be understood in light of recent historicised understandings of the emergence of bioethics, as an exercise in public deliberation and policy-making distinct from its various antecedents. It is not solely the province of health professionals, nor of philosophers, nor of law-makers, but a meeting point for discussion and the formulation of what might be termed compromise policies.

It is possible thus to describe the nature of the bioethical enterprise in terms of both reasons for inquiry and the interpretation of results. Perhaps we can look beyond questions of disciplinary approach and immediate research objectives to commonalities of subject matter and the overall goals of knowledge production. To do this, however, the hurdles of methodological and disciplinary difference must first be assessed and addressed or at least circumvented. Given the centrality of methodology to the production and validation of knowledge within social science disciplines, versus the broad and often unexplicated approach to 'methodology' common within analytic philosophy, it is unsurprising that debates over disciplinarity and methodology have become so entangled when it comes to questioning the role of both in bioethics. This raises the question of the importance of methodology to disciplinary identity, and its proper role within something we would characterise as a field of study, or, as we have put it in this editorial, an 'enterprise'. Framing a research question is an important part of the research process and demonstrates how disciplinarity is entwined with methodology: the need to design questions that can be answered using the knowledge base, skills, and methods of the discipline. But what does this mean for bioethics, which is not easily viewed as a discipline at all, but a field of study, or a disciplinary meeting place, as some of our authors express it?

As disciplinarity in research not only influences the methodologies we use to seek answers but also shapes the very questions we ask, inter- (emphatically as opposed to multi-) disciplinarity potentially requires a rethinking of our approaches to 
generating knowledge: what kinds of understandings are we trying to produce and why? This entails not just new ways of solving problems but a new approach to defining what the problems are. Part of the communication question is in defining research agendas, and explicating the reasons to find them valuable. The central challenge in this regard is whether bioethics can be multifaceted in its objectives, as well as its methods and approaches to knowledge production. The papers in this special issue strongly indicate that, almost certainly, it can.

By addressing the sorts of questions we raise in this editorial, the contributors to this journal issue present a range of perspectives in terms of both the disciplinary (and in many cases multidisciplinary) backgrounds of the authors themselves and the view(s) of bioethics for which they argue. In some cases there are tensions between their different accounts of what bioethics is or should be for, and how it relates to or encompasses other disciplines. These differences, we hope, prove to be informative rather than fatal to our overall project, of trying to imagine, define and explore the myriad notions of what 'counts', in all the possible senses of the word, as bioethics.

Acknowledgments The editors would like to thank the Wellcome Trust Strategic Programme on 'The Human Body: Its scope, limits and future' (Grant number WT087439/Z/08/Z) and the University of Manchester's 'methods@manchester' programme for their support of the workshop that led to the publication of this Special Issue. 